\title{
The Effect of Comedy Videos in Alleviating Post Operative Pain
}

\author{
Dr.T.Srinivasan ${ }^{1}$, Dr.M.Muralidharan ${ }^{2}$ \\ ${ }^{I}$ (Senior Assistant Professor of Surgery, Department Of General Surgery, Coimbatore Medical College \\ Coimbatore. / Tamilnadu M.G.R University, India) \\ ${ }^{2}$ ( Post Graduate, Department Of General Surgery, Coimbatore Medical College/ Tamilnadu M.G.R University, \\ India)
}

\begin{abstract}
Humour is considered as an universal language. It influences the human life at various stages. A randomized controlled study involving 90 patients who were to undergo surgery was conducted at Coimbatore Medical College Hospital,Coimbatore.45 patients selected at random and were exposed to the comedy videos which was played at their bedside from admission to one day post operatively and they receive analgesic immediately after surgery and further pain was assessed using VAS and if needed analgesics given and recorded in observational chart. The control group of 45 patients did not see the videos during their stay in the hospital and received routine analgesic dosages at timed dosage schedule. An observation chart was attached in which the requirement of analgesics by the patient and pain was assessed during 0, 3, 6, 12, 24 hours post operatively using visual analogue scale. On completion of the study and on analysis,playinghumour videos had a significant effect in post operative pain management which was evidenced by the reduction in analgesic requirement by $50 \%$ in those who watched humourvideos. A significant $p$ value of $<0.001$ was obtained.
\end{abstract}

Keywords: humour videos, Pain management, Post operative pain, virtual reality, Analgesic requirement

\section{Introduction}

There has recently been heightened recognition that environmental factors can influence pain. Clinicians involved in delivering multidisciplinary pain ${ }^{(1)}$ programs often structure the social environment of their treatment settings to help promote adaptive responses to pain. Recent theories of pain (e.g. Craig, 2003, Melzack, 1999, Fields \&Basbaum, 1999) highlight the role that sensory stimuli from the environment can play in influencing the pain experience.Despite the awareness if the environment's influence on pain, patients with pain continue to be treated in settings that are devoid of distracting stimuli. The typical treatment room is painted white, lacking decoration, sparsely furnished, and windowless. The visual and sensory settings in which we usually treat pain patients probably do little to relieve pain and may exacerbate pain.This paper considers the influence of environmental stimuli mainly video and virtual reality (VR) stimuli ${ }^{(2)}$ on pain and examines the implications for designing pain treatment environments to enhance pain control.

Video and VR methods expose persons to interesting and distracting ${ }^{(3)}$ environments. Miller, Hickman, and Lemasters (1992) tested the effects of video visual and music presentation on pain and anxiety in burn ${ }^{(4)}$ patients. Seventeen patients were randomly assigned to videos of scenic imagery and music during dressing changes or to a usual care control group. Patients exposed to the video reported significant reductions in ratings of pain intensity, pain quality, and anxiety during dressing changes.

A recent study examined the differential impact of visual distraction (e.g., headset that screened out external simuli and provided visual stimuli ${ }^{(5)}$ ), audiovisual distraction (e.g., visual distraction accompanied by classical music), and no distraction on the use of patient controlled sedation medication and pain during elective colonoscopy (Lee et al., 2004). Patients who received audiovisual distraction used less sedative medication and reported less pain than individuals who received only video distraction or no distraction. Environments that combine visual and audio stimuli may be more effective in decreasing pain.

Hoffman, Patterson, and Carrougher (2000) conducted one of the first controlled investigations testing the efficacy of VR as a method of pain relief in burn patients undergoing physical therapy. VR produced significant decreases in pain intensity, pain unpleasantness, and time spent thinking about pain. Patients who reported high levels of feeling as though they were actually in the VR environment ${ }^{(6)}$ showed the greatest decreases in pain and anxiety.

Wolitzky et al. (2005) conducted a study of VR in pediatric oncology patients undergoing a port access procedure. The VR intervention consisted of a scene from a zoo that children could view, hear, interact with, and travel through. Children receiving the intervention showed significant reductions in pain and pulse before and after the procedure.

Viewing nature scenes may decrease pain perceptions by eliciting positive emotional responses and decreasing stress. Prospective environmental studies suggest that briefly viewing nature ${ }^{(7)}$ can produce rapid and significant recovery from stress. Blood pressure typically declines within three minutes of viewing 
unspectacular nature. Fredrickson and Levenson (1998) showed participants a scary, stressful film and reported that persons assigned to view a nature video evidenced recovery from cardiovascular stress in about 20 seconds. Video or VR presentations provide a relatively inexpensive strategy for pain relief ${ }^{(8)}$. When designing treatment facilities, portable video ${ }^{(9)}$ or VR kiosks could made available throughout facilities to provide environments that can aid in the control of pain.

Past work has provided information on how to most effectively implement video ${ }^{(10)}$ and VR presentation. First, many patients undergo several treatment procedures that increase pain and repeated viewing of material decreases the positive effects (Miller et al., 1992). Alternative video material (e.g., sports, comedy) should be available to decrease habituation effects. Next, evidence suggests that video and VR presentations for pain should fully engage the patient by stimulating visual, auditory and tactical senses (Hoffman et al., 2000). Future research should assess the effects of different environments created with VR, and whether it is beneficial in terms of pain control for patients to choose what they view.

An observation chart was attached to the questionnaire in which the requirement of analgesics by the patient was recorded.

\section{Objectives Of The Study}

To study the nonrequirement or the reduction in requirement of analgesics in patients subjected to humour videos (Humour group) in post operative period.

To analyse the potentiation of analgesic effect by humour videos and compare the requirement of analgesics with a group of patients not subjected to humour videos and received analgesics (control group).

\section{Methodology}

Study site-Coimbatore Medical College Hospital, Coimbatore

Duration of the study-march-2016 to July-2016

A randomized controlled study involving 90 patients who were to undergo surgery was conducted at Coimbatore Medical College Hospital, Coimbatore. 45 patients selected at random and were exposed to the humour videos which was played at their bedside from admission to one day post operatively and they receive analgesic immediately after surgery and further at 3,6,12,24 hours their pain was assessed using VAS and if needed analgesics given and recorded in observational chart.. The control group of 45 patients did not see the videos during their stay in the hospital and received routine analgesic dosages at timed dosage schedule. An observation chart was attached in which the requirement of analgesics by the patient and pain was assessed during $0,3,6,12,24$ hours post operatively using visual analogue scale.

An observation chart was attached in which the requirement of analgesics by the patient was recorded.

\section{Inclusion Criteria}

Patients undergoing Surgeries included in the study were,Hernia surgeriesAppendicectomyThyroidectomyBreast surgeries (excluding mastectomy)Ninety patients who were to undergo a surgery were chosen to be part of the study.

- $\quad$ Aged 18 years and above.

- $\quad$ Between march-2016 to may-2016.

\section{Exclusion Criteria}

- Patients who are below 18 years.

- Pregnant patients.

\section{Outcome}

Requirement of analgesic and experience of pain relief by patient was analysed using visual analogue scale for pain and observational chart.

\section{Statistical Analysis}

A student's $t$-test (SEDM-standard error of difference in means) was used to find out whether the difference in the analgesic requirement of the control and study groups was statistically significant. Statistical probability of $P<0.05$ was considered to be significant.

The age and sex distribution of the sample and the influence of exposure to humour videos among the groups were determined from the information obtained.

\section{Observation And Results}

Table 1: Requirement of analgesic doses in control and humour group. 


\begin{tabular}{|c|c|c|}
\hline \multicolumn{3}{|c|}{ Requirement of analgesics } \\
\hline \multirow[t]{2}{*}{ S.No } & \multicolumn{2}{|c|}{ Analgesics doses required } \\
\hline & Control & Humour \\
\hline 1 & 3 & 1 \\
\hline 2 & 3 & 1 \\
\hline 3 & 3 & 1 \\
\hline 4 & 4 & 2 \\
\hline 5 & 3 & 1 \\
\hline 6 & 3 & 1 \\
\hline 7 & 2 & 1 \\
\hline 8 & 3 & 2 \\
\hline 9 & 3 & 3 \\
\hline 10 & 1 & 1 \\
\hline 11 & 2 & 1 \\
\hline 12 & 2 & 1 \\
\hline 13 & 3 & 1 \\
\hline 14 & 4 & 1 \\
\hline 15 & 3 & 1 \\
\hline 16 & 4 & 2 \\
\hline 17 & 5 & 2 \\
\hline 18 & 4 & 1 \\
\hline 19 & 3 & 1 \\
\hline 20 & 3 & 2 \\
\hline 21 & 4 & 1 \\
\hline 22 & 3 & 2 \\
\hline 23 & 4 & 1 \\
\hline 24 & 3 & 2 \\
\hline 25 & 3 & 1 \\
\hline 26 & 4 & 2 \\
\hline 27 & 3 & 1 \\
\hline 28 & 4 & 1 \\
\hline 29 & 5 & 3 \\
\hline 30 & 4 & 1 \\
\hline 31 & 3 & 1 \\
\hline 32 & 3 & 1 \\
\hline 33 & 4 & 1 \\
\hline 34 & 3 & 2 \\
\hline 35 & 4 & 2 \\
\hline 36 & 3 & 1 \\
\hline 37 & 2 & 1 \\
\hline 38 & 2 & 2 \\
\hline 39 & 3 & 3 \\
\hline 40 & 4 & 1 \\
\hline 41 & 3 & 1 \\
\hline 42 & 4 & 1 \\
\hline 43 & 3 & 1 \\
\hline 44 & 2 & 1 \\
\hline 45 & 3 & 2 \\
\hline
\end{tabular}

Table 2: Age and sex distribution in control and humour group.

\begin{tabular}{|c|c|c|c|c|}
\hline \multicolumn{5}{|c|}{ AGE \& SEX DISTRIBUTION } \\
\hline \multirow[t]{2}{*}{ AGE GROUP } & \multicolumn{2}{|c|}{ CONTROL } & \multicolumn{2}{|c|}{ HUMOUR } \\
\hline & MALE & FEMALE & MALE & FEMALE \\
\hline$<20$ & 1 & 0 & 0 & 1 \\
\hline $20-30$ & 3 & 2 & 4 & 3 \\
\hline $30-40$ & 6 & 5 & 5 & 4 \\
\hline $40-50$ & 5 & 7 & 6 & 6 \\
\hline $50-60$ & 5 & 3 & 7 & 4 \\
\hline$>60$ & 4 & 4 & 3 & 2 \\
\hline
\end{tabular}

Fig 1: Age and sex distribution in control and humour group. 


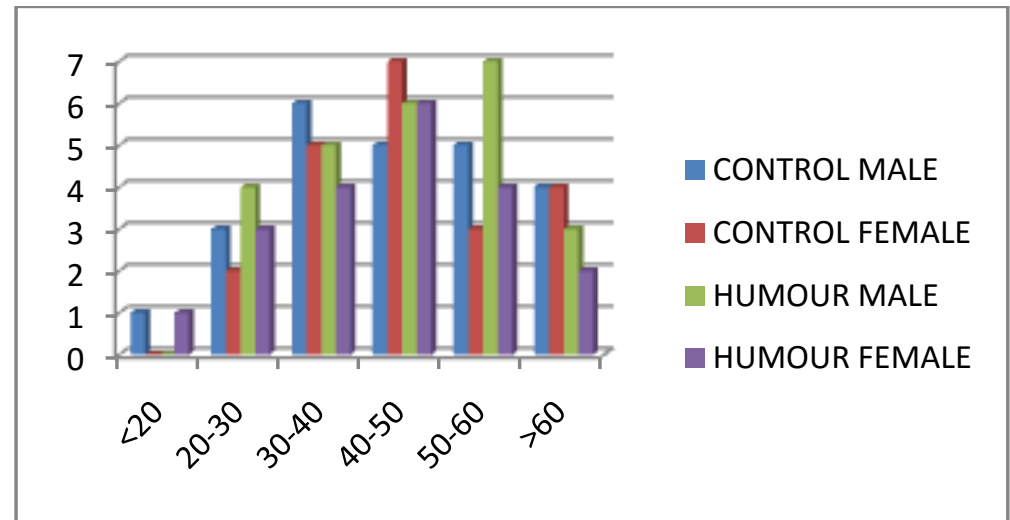

Table 3: Mean analgesic dose requirement in control and humour group.

\begin{tabular}{|l|l|}
\hline \multicolumn{2}{|l|}{ MEAN ANALGESIC DOSE REQUIREMENT } \\
\hline & mean of the analgesic dose required \\
\hline control & 3.2 \\
\hline humour & 1.4 \\
\hline
\end{tabular}

Fig 2: Mean analgesic dose requirement in control and humour group.

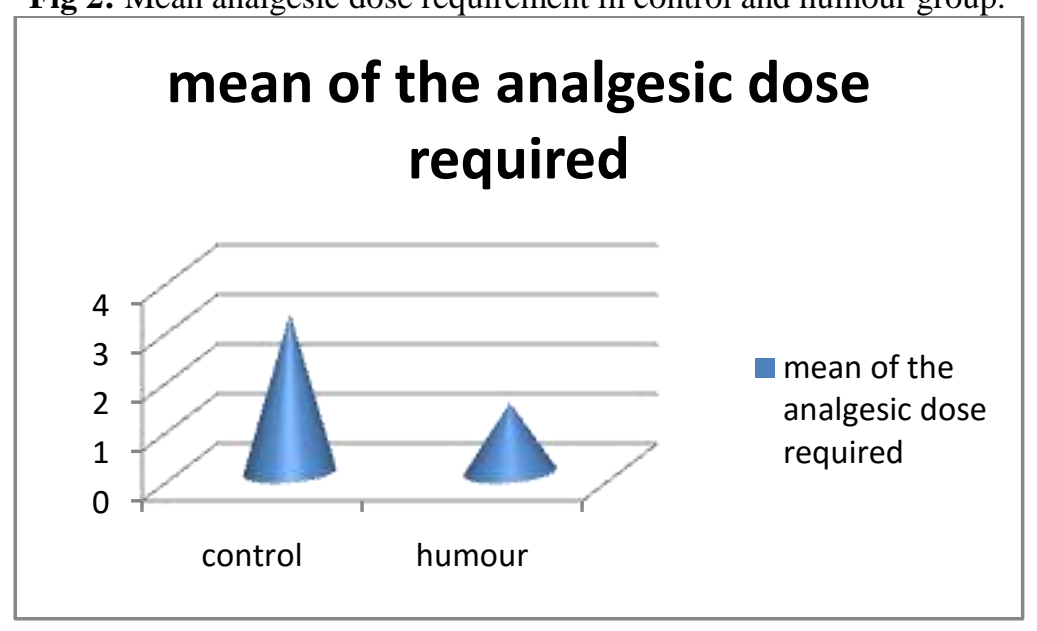

\section{Conclusion}

Exposure to humour videos has an effect in postoperative pain management which is evidenced by the reduction in analgesic requirement by $50 \%$ in those who watched humour videos postoperatively. A significant $P$ value of $<0.001$ was obtained.

\section{References}

[1]. Fields HL, Basbaum A. Central nervous system mechanisms of pain modulation. In: Wall PD, Melzack R, editors. Textbook of Pain. Churchill Livingstone; Edinburgh: 1999. pp. 309-329. 1999.

[2]. Hoffman HG, Patterson DR, Carrougher GJ. Use of virtual reality for adjunctive treatment of adult burn pain during physical therapy: a controlled study. Clin J Pain. 2000;16:244-250.[PubMed]

[3]. Lee DWH, Chan ACW, Wong SKH, Fung TMK, Li ACN, Chan SKC, Mui LM, Ng EKW, Chung SCS. Can visual distraction decrease the dose of patient-controlled sedation required during colonoscopy? A prospective randomized controlled trial. Endoscopy. 2004;36:197-201.[PubMed]

[4]. Miller AC, Hickman LC, Lemasters GK. A distraction technique for control of burn pain. J Burn Care Rehabil. 1992;13:57681.[PubMed]

[5]. Tse MMY, Ng JKF, Chung JWY, Wong TKS. The effect of visual stimuli on pain threshold and tolerance. J ClinNurs. 2002;11:264-69.[PubMed]

[6]. Ulrich R. View through a window may influence recovery from surgery. Science. 1984;224:420-1.[PubMed]

[7]. Walch JM, Rabin BS, Day R, Williams JN, Choi K, Kang JD. The effect of sunlight on postoperative analgesic medication use: A prospective study of patients undergoing spinal surgery. Psychosom Med. 2005;67:156-63.[PubMed]

[8]. Wilson EO. Biophilia. Harvard University Press; Cambridge, Mass.: 1984. p. 176.

[9]. Wolitzky K, Fivush R, Zimand E, Hodges L, Rothbaum BO. Effectiveness of virtual reality distraction during a painful medical procedure in pediatric oncology patients. Psychology and Health. 2005;6:817-824.

[10]. Yamada N, Martin-Iverson MT, Daimon K, Tsujimoto T, Takahashi S. Clinical and chronobiological effects of light therapy on nonseasonal affective disorders. Biol Psychiatry. 1995;37:866-73.[PubMed] 